\title{
ESPESSAMENTO MÉDIO-INTIMAL CAROTÍDEO EM CRIANÇAS COM DIFERENTES DOENÇAS DE CARÁTER INFLAMATÓRIO: 0 QUANTO PREDIZ 0 FUTURO DE SUAS ARTÉRIAS?
}

\section{Isabela de Carlos Back Giuliano, Ana Paula freund Winneschhofer, Bruno Caramell}

Trabalho realizado no Hospital Infantil Joana de Gusmão, Florianópolis, SC

Crescem as evidências sobre a aterogênese desde a vida intrauterina, sendo descrito aterosclerose subclínica na infância em diversas doenças de caráter inflamatório. A Figura IA demonstra a espessura médio-intimal cartotídea (EMIC) de uma menina de cincoanos de idade com um tumor de supra-renal metastático, ativo desde um ano de idade, que não recebeu radioterapia em segmento cefálico, com EMIC de 54 I $\mu \mathrm{m}$. A Figura IB e IC mostram a EMIC de um menino de I2 anos com Aids, adquirida por transmissão materno-fetal, medindo $498 \mu \mathrm{m}$ e a EMIC de uma adolescente de 13 anos, portadora de insuficiência renal crônica e hipertensão arterial, medindo $512 \mu \mathrm{m}$. As duas últimas doenças têm sido associadas com aceleração da progressão da aterosclerose, mesmo durante a infância 1,2. Para comparação adicional, a Figura IDapresenta a EMIC de uma adolescente de I 4 anos aparentemente saudável, com espessura de $288 \mu \mathrm{m}$. Considera-se o ponto de corte de $490 \mu \mathrm{m}$ como critério de normalidade até os 18 anos $^{3}$. Considerando que a sobrevida do câncer tem aumentado nos últimos anos, transformando-se numa doença crônica em alguns casos, a monitoração e a prevenção da aterosclerose também é necessária nesses pacientes, como em todos os outros acometidos por doenças que apresentam um estado inflamatório subagudo.

\section{Referências}

I. Charakida M, Donald AE, Green H, Storry C, Clapson M, Caslake M, et al. Early structural and functional changes of the vasculature in HIV-infected children: impact of disease and antiretroviral therapy. Grculation 2005; I I 2( I): 1 03-9.

2. Ece A, Gurkan F, Kervancioglu M, Kocamaz H, Gunes A, Atamer Y, et al. Oxidative stress, inflammation and early cardiovascular damage in children with chronic renal failure. Pediatr Nephrol 2006;2 I (4):545-52.

3. Jourdan C, Wuhl E, Litwin M, Fahr K, Trelewicz J, Jobs K, et al. Normative values for intima-media thickness and distensibility of large arteries in healthy adolescents. J Hypertens 2005;23(9): I 707- 15.
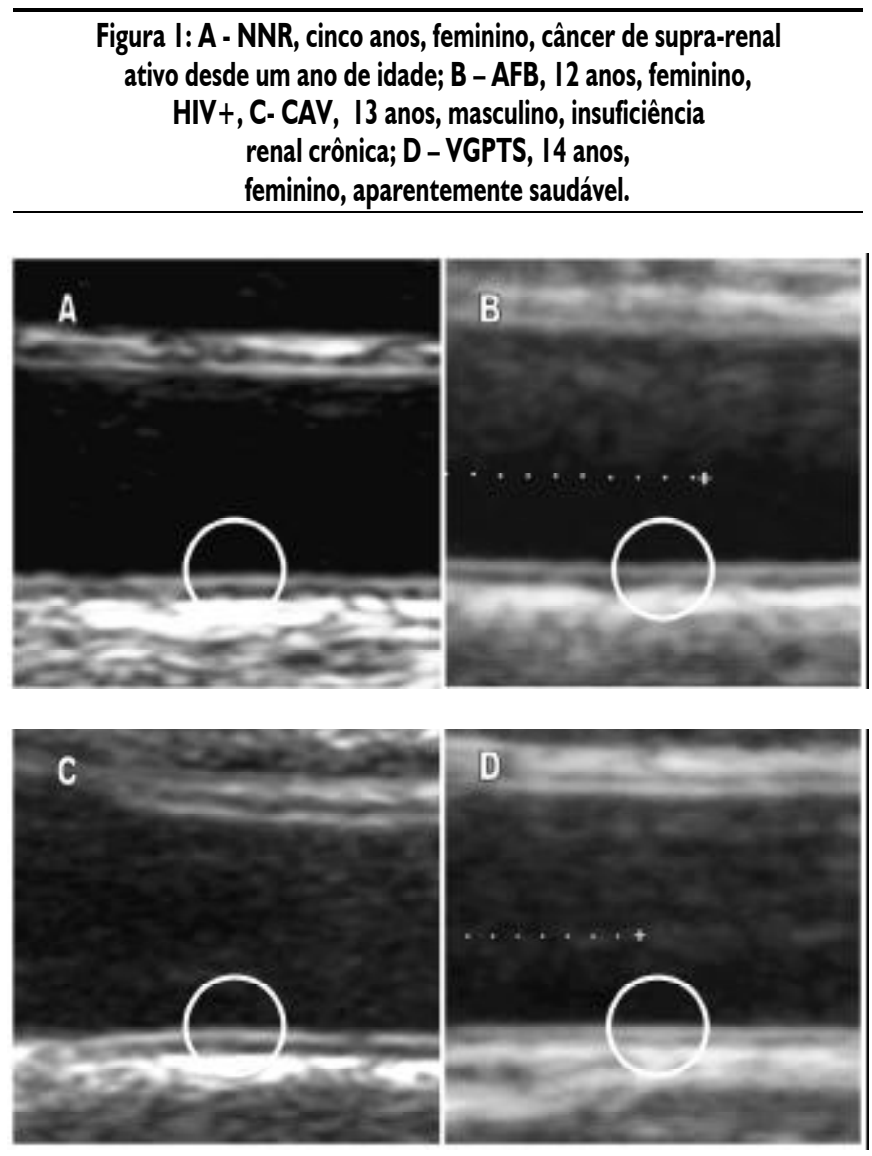